\title{
Trauma patterns during the COVID-19 lockdown in South Africa expose vulnerability of women
}

\author{
A Zsilavecz, ${ }^{1} \mathrm{MB}$ ChB; H Wain, ${ }^{1} \mathrm{MB}$ BCh; J L Bruce, ${ }^{1} \mathrm{MB}$ ChB, FCS (SA); M T D Smith, ${ }^{1}$ MB ChB, FCS (SA), MMed (Surgery); \\ W Bekker, ${ }^{1}$ MB ChB, FCS (SA), Cert Trauma Surgery (SA), MMedSci (Surgery); G L Laing, ${ }^{1}$ MB ChB, MSc, FCS (SA), Cert Trauma Surgery (SA); \\ E Lutge, ${ }^{2,3}$ MB ChB, PhD, MSc, FCPHM; D L Clarke, ${ }^{1,3,4,5}$ MB BCh, MPhil, MBA, PhD, FCS (SA) \\ ${ }^{1}$ Department of Surgery, Grey's Hospital, Pietermaritzburg, South Africa \\ ${ }^{2}$ Epidemiology Unit, KwaZulu-Natal Department of Health, Pietermaritzburg, South Africa \\ ${ }^{3}$ School of Nursing and Public Health, College of Health Sciences, University of KwaZulu-Natal, Durban, South Africa \\ ${ }^{4}$ University of KwaZulu-Natal, Durban, South Africa \\ ${ }^{5}$ Department of Surgery, Faculty of Health Sciences, University of the Witwatersrand, Johannesburg, South Africa
}

Corresponding author: A Zsilavecz (azsilavecz@gmail.com)

Background. Trauma care places a significant burden on the South African (SA) healthcare system, and this has not changed significantly in recent history. We speculated that the COVID-19 lockdown regulations (travel restriction and alcohol ban) would affect trauma patterns. Objectives. To compare the burden and nature of trauma over the COVID-19 lockdown period with the equivalent period over the past 5 years using routinely collected data from the Pietermaritzburg Metropolitan Trauma Service in KwaZulu-Natal Province, SA.

Methods. All trauma patients admitted to Grey's Hospital in Pietermaritzburg between 23 March 2015 and 31 May 2020 were identified and reviewed.

Results. A total of 8859 trauma patients were admitted over the 6-year period, with a total of 1676 admitted during the periods 23 March 31 May. These 1676 formed the study cohort. Of these patients, 998 had sustained blunt trauma, 665 penetrating trauma, and 13 a combination of blunt and penetrating trauma. A total of 14 categories of blunt trauma were reviewed, of which the three most common were assault, motor vehicle accidents (MVAs) and pedestrian vehicle accidents (PVAs). Between 23 March and 31 May 2020 , a total of 23 patients were victims of blunt assault. The median number of assault victims over the equivalent period during the previous 5 years was 48 . The 5 preceding years had a median of 56 MVAs and 33 PVAs, compared with 23 and 10 during the lockdown. The median number of gunshot wound (GSW) victims for the preceding years was 41, compared with 30 during the lockdown. During the lockdown, 24 stab wound victims were admitted, compared with a median of 73 for the preceding years. The proportion of females who sustained penetrating trauma and blunt assault increased significantly during the lockdown. The proportion of females sustaining a GSW or blunt trauma secondary to an MVA remained constant.

Conclusions. The study showed that during the period of lockdown in SA there was a significant decrease in MVAs, PVAs and interpersonal violence. Assaults involving a knife seemed to decrease dramatically, but the rate of GSWs remained constant.

S Afr Med J 2020;110(11):1110-1112. https://doi.org/10.7196/SAMJ.2020.v110i11.15124

Trauma in South Africa (SA) remains the 'neglected malignant epidemic', with stubbornly high levels of interpersonal violence and road traffic-related injury persisting for over four decades. ${ }^{[1-7]}$ Although this excessive burden of trauma in SA has been extensively documented for more than 40 years, trauma has never been recognised as a defined problem that deserves to be the focus of a sustained multifaceted cross-sectoral prevention programme. Over the past quarter of a century, sustained policy drift, political inertia and a generalised fatalistic approach have allowed this massive burden to persist and even expand. The recent COVID-19-related crisis has resulted in dramatic and unprecedented public health interventions being implemented by governments, state actors and supranational organisations across the globe. In SA, a national lockdown was announced on 23 March 2020, and came into effect at midnight on 26 March. It confined all citizens who were not performing an essential service to their homes, and completely banned the sale and public consumption of alcohol. In addition, strict travel regulations and limitations on public gatherings were implemented. These regulations were strictly enforced by both the army and the police service. Easing of the lockdown regulations came into effect on 1 June 2020, including resumption of the sale of alcohol at certain times of the day and on certain days of the week, a relaxation of travel restrictions, and re-opening of much of the commercial sector. In a sense, the lockdown can be regarded as the implementation of an unprecedented, inadvertent and unexpected social experiment on a national scale. It can also be viewed as a major injury prevention programme, as by eliminating alcohol and limiting travel, two of the major facilitators of trauma were drastically reduced.

\section{Objectives}

The lockdown restrictions presented a unique opportunity to the trauma surgery community, in that they allowed assessment of the impact of nationally mandated travel and alcohol restrictions on trauma patterns in SA. It is vitally important that we do not waste this opportunity, and review the impact of the lockdown to identify insights and evidence that can provide data to help with the development of future social policies in SA. Using routinely collected data from the Pietermaritzburg Metropolitan Trauma Service (PMTS) in KwaZulu-Natal (KZN) Province, this study sought to compare the burden and nature of trauma over the months of March - May during the lockdown period with the equivalent period over the past 5 years. 


\section{Methods}

The PMTS provides definitive trauma care to the city of Pietermaritzburg, the capital of KZN. It is one of the largest academic trauma centres in KZN. The PMTS serves as a tertiary referral centre for 19 rural hospitals in KZN, with a total catchment population of three million people. The Hybrid Electronic Medical Registry is a formal regional registry of all patients presenting to this trauma centre. All patient data are prospectively captured; this system has been described previously in the literature. ${ }^{[5,6]}$ The database includes information on the mechanism of injury, operative intervention and clinical outcome.

All trauma patients admitted to Grey's Hospital in Pietermaritzburg between 23 March 2020 and 31 May 2020 were identified and reviewed. All trauma patients for the equivalent period from 2015 to 2019 were also reviewed. We analysed basic demographic data, mechanism of injury, physiological values on admission, and all operative interventions. Details of the mechanism of injury, the nature of the injury and the type of operative intervention were recorded. The absolute numbers as well as the proportions of each mechanism were then compared. The pre-lockdown values were expressed as a 5 -year mean. A gender-based comparison of the absolute numbers and proportions of total trauma admissions according to each mechanism was performed. The $\chi^{2}$ test was used to compare distributions of categorical variables, and the alpha level was set at 0.05 . Mechanisms of injury were expressed as percentages of overall injuries.

Ethics approval for this study and the maintenance of the registry was obtained from the Biomedical Research Ethics Committee of the University of KwaZulu-Natal (ref. nos BE 207/09 and BCA 221/13).

\section{Results}

Of the 8859 trauma admissions over the 6 years investigated, a total of 1676 patients were admitted over the period 23 March - 31 May during the 6 years under review. This was the study cohort. Of these, 998 had sustained blunt trauma, 665 penetrating trauma and 13 a combination of blunt and penetrating trauma. The three most common categories of blunt trauma were assault, motor vehicle accident (MVA) and pedestrian vehicle accident (PVA) (Fig. 1).

During the lockdown period, a total of 23 patients were victims of blunt assault. The median number of blunt assault victims for the equivalent period over the previous 5 years was 48 . Numbers of MVAs and PVAs over the lockdown period were 23 and 10, respectively, compared with 56 and 33 over the preceding 5 years. There were 30 gunshot wound (GSW) victims during the lockdown, compared with a median of 41 over the previous 5 years. The respective figures for stab wounds were 24 and 73 (Fig. 2).

Table 1 provides a comparative overview of the mechanisms of trauma during the lockdown and the equivalent period over the previous 5 years. The overall proportion of male and female patients, and the overall proportion of blunt trauma and assault, did not change. Levels of road traffic collisions (MVAs plus PVAs) and stab wounds decreased significantly during the lockdown period in comparison with the equivalent period during the previous 5 years. The proportion of GSWs increased significantly during the lockdown period. The contribution of GSW to the total burden of penetrating trauma increased significantly from $33.1 \%$ during the non-lockdown period to $49.2 \%$ during the lockdown period, as a result of the overall decrease in the number of stab wounds.

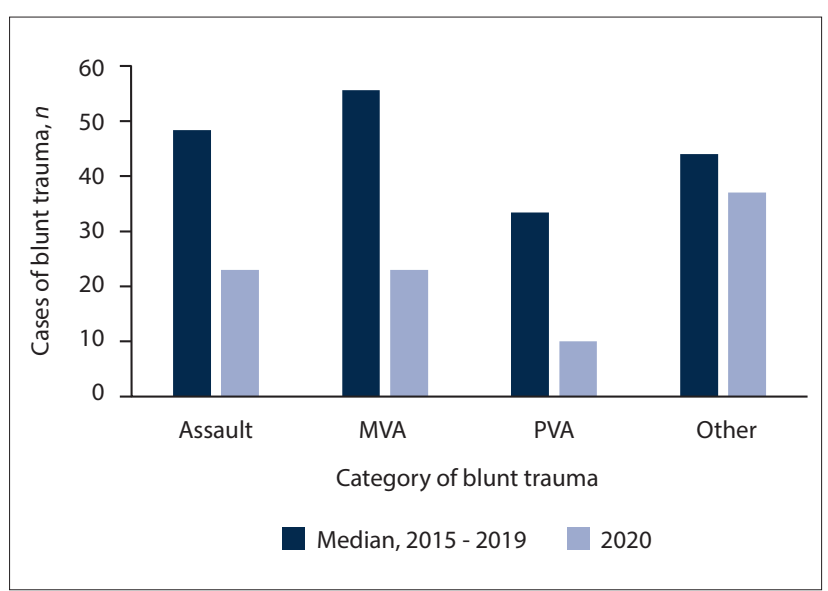

Fig. 1. Blunt trauma over the periods 23 March - 31 May during 2015 2019 and 23 March - 31 May 2020. (MVA = motor vehicle accident; $P V A=$ pedestrian vehicle accident.)

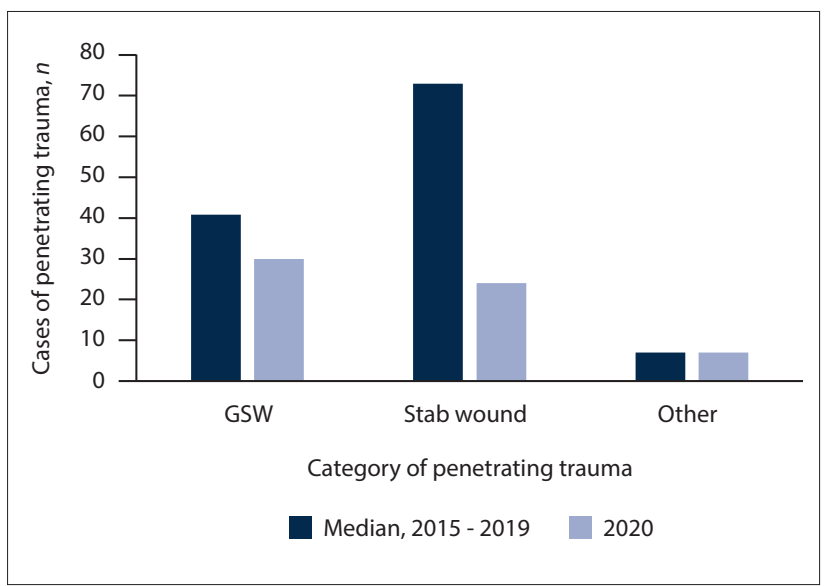

Fig. 2. Penetrating trauma over the periods 23 March - 31 May during 2015 2019 and 23 March - 31 May 2020. (GSW = gunshot wound.)

Table 1. Proportional comparison of trauma cases over the period 23 March - 31 May during and before lockdown ${ }^{\dagger}$

\begin{tabular}{|c|c|c|c|}
\hline & Lockdown $(N=154)$ & Pre-lockdown 5-year mean $(N=304)$ & $p$-value \\
\hline Male, \% & $76.0(n=117)$ & $80.8(n=246)$ & \\
\hline Female, \% & $24.0(n=37)$ & $19.2(n=58)$ & 0.15 \\
\hline Total blunt trauma, \% & 60.4 & $59.5(n=181)$ & 0.82 \\
\hline Total assault (blunt plus penetrating), \% & 14.9 & $15.9(n=48)$ & 0.68 \\
\hline RTCs, \% & 21.4 & $29.2(n=89)$ & $0.041^{\star}$ \\
\hline GSWs, \% & 19.5 & $13.4(n=41)$ & $0.038^{*}$ \\
\hline SWs, \% & 15.6 & $24.0(n=73)$ & $0.019^{*}$ \\
\hline Penetrating injuries, proportion of GSWs to SWs & $49.2 / 50.8$ & $33.1 / 66.9$ & $0.012^{\star}$ \\
\hline
\end{tabular}


Table 2. Gender differences in trauma cases over the period 23 March - 31 May during and before lockdown ${ }^{\dagger}$

\begin{tabular}{|c|c|c|c|c|c|}
\hline & \multicolumn{2}{|c|}{ Lockdown, $n(\%)$} & \multicolumn{2}{|c|}{ Pre-lockdown, 5-year mean, $n(\%)$} & \multirow[b]{2}{*}{$p$-value } \\
\hline & Male & Female & Male & Female & \\
\hline Blunt assault & $17(73.9)$ & $6(26.1)$ & $43(88.8)$ & $0.4(11.2)$ & $0.038^{*}$ \\
\hline Penetrating trauma & $48(78.7)$ & $13(21.3)$ & $109.4(88.7)$ & $14(11.3)$ & $0.023^{*}$ \\
\hline GSWs & $23(76.7)$ & $7(23.3)$ & $35.2(86.3)$ & $5.6(13.7)$ & 0.168 \\
\hline RTCs & $24(72.7)$ & $9(27.3)$ & $58.8(66.1)$ & $30.2(33.9)$ & 0.434 \\
\hline
\end{tabular}

Table 2 compares the proportion of male and female victims of the different modalities of trauma. The proportion of females who sustained penetrating trauma and blunt assault increased significantly during the lockdown period. The proportion of female patients sustaining a GSW or blunt trauma secondary to an MVA remained constant.

\section{Discussion}

Poorly enforced traffic regulations, in conjunction with rapid urbanisation and increased rates of motor vehicle ownership, have resulted in high rates of motor vehicle-related trauma and injury in SA. The lockdown effectively eliminated all but essential road travel in the country, which translated into significant decreases in PVAs and MVAs during the lockdown period. This finding suggests that motor vehicle-related injury can be reduced by more aggressive enforcement of road traffic regulations, provided there is the political will and funding, together with a major change in the culture of road usage in the country.

Interpersonal violence in $\mathrm{SA}$ is a vexing issue that has no single explanation. What is obvious is that the high levels of interpersonal violence are part and parcel of SA life and seem embedded in the cultural milieu of the country. Of all the categories of trauma, interpersonal violence is perhaps least amenable to injury prevention programmes, because human behaviour is difficult to modify. Most strategies attempt to limit access to dangerous weapons such as guns and knives. Restrictive firearm legislation has been in force in SA for well over a decade. There is evidence that this did reduce the burden of GSWs, but current data suggest that the level of GSWrelated trauma in our region remains significant. The proportional increase in GSWs and the significant decrease in stab wounds during the lockdown period suggest that there may well be a premeditated component to firearm-related violence as opposed to that involving a knife. Reduced social encounters outside the home seem to reduce the incidence of knife trauma.

The excessive burden of interpersonal violence in SA affects a number of vulnerable groups. ${ }^{[8]}$ While young males are traditionally the most common victims of interpersonal violence, they are also most likely to be its perpetrators. The burden of female trauma often tends to get overlooked. This is egregious, as although females sustain interpersonal violence much less frequently than young males, they are very seldom the perpetrators of this violence and are almost exclusively the victims. This is known as gender-based violence, as women sustain their injuries at the hands of men. Our data highlight that the proportion of female victims of trauma, especially blunt assault and penetrating trauma, increased significantly during the lockdown. Our findings suggest that women encounter trauma at home, whereas men encounter it outside the home. It appears that women are not safe in their places of residence, and that genderbased violence is perpetrated in the home by people with whom women live.

\section{Conclusions}

This study highlighted that during the period of lockdown in SA there was a significant decrease in MVAs, PVAs and interpersonal violence. Knife crime appeared to decrease dramatically, but the rate of GSWs remained constant. The proportion of trauma cases in which a woman was the victim increased dramatically, confirming concerns that the lockdown period was dangerous to women.

Declaration. None.

Acknowledgements. None.

Author contributions. AZ, HW: concept development, data cleaning, manuscript. JLB, GLL, WB, EL: concept development. DLC: concept development, manuscript supervision, project supervision. MTDS; data analysis.

Funding. None.

Conflicts of interest. None.

1. Clarke DL. 'The malignant epidemic' still the neglected stepchild. S Afr J Surg 2017;55(4):2.

2. Moodley NB, Aldous C, Clarke DL. An audit of trauma-related mortality in a provincial capital in South Africa. S Afr J Surg 2014;52(4):101-104. https://doi.org/10.7196/sajs.1995

3. Hardcastle TC, Samuels C, Mukart DJ. An assessment of the hospital disease burden and the facilities for the in-hospital care of trauma in KwaZulu-Natal, South Africa. World J Surg 2013;37(7):15501561. https://doi.org/10.1007/s00268-012-1889-1

4. Norman R, Matzopoulos R, Groenewald P, et al. The high burden of injuries in South Africa. Bull World Health Organ 2007;85(9):695-702. https://doi.org/10.2471/BLT.06.037184

5. Laing GL, Bruce JL, Aldous C, Clarke DL. The design, construction and implementation of a computerized trauma registry in a developing South African metropolitan trauma service. Injury 2014;45(1):3-8. https://doi.org/10.1016/j.injury.2013.05.013

6. Donovan MM, Kong VY, Bruce JL, et al. The Hybrid Electronic Medical Registry allows benchmarking of quality of trauma care: A five-year temporal overview of the trauma burden at a major trauma centre in South Africa. World J Surg 2019;43:1014-1021. https://doi.org/10.1007/ a major trauma cen-

7. Lutge E, Moodley N, Tefera A, Sartorius B, Hardcastle T, Clarke D. A hospital based surveillance Lutge E, Moodley N, Tefera A, Sartorius B, Hardcastle T, Clarke D. A hospital based surveillance
system to assess the burden of trauma in KwaZulu-Natal Province South Africa. Injury 2016;47(1):135-140. https://doi.org/10.1016/j.injury.2015.08.020

8. Khumalo-Mugabi L, Moffatt S, Bekker W, et al. Penetrating trauma in children and adolescents in Pietermaritzburg. S Afr J Surg 2020;58(1):33-36. https://doi.org/10.17159/2078-5151/2020/v58n1a3017

Accepted 21 September 2020. 